\title{
Educação e Direitos para (in) Humanos? Desafios e Reflexões sobre os Dilemas de LGBT"s perante o Discurso Jurídico Brasileiro
}

\author{
Simone Becker ${ }^{7}$ \\ Esmael Alves de Oliveira ${ }^{2}$
}

\section{Resumo}

Este artigo é o resultado de pesquisas e de diálogos sobre educação e direitos humanos entre os autores a partir de suas incursões pelos estudos de gênero e sexualidade. Todos os movimentos aqui delineados (no sentido deleuziano/guattariano para rizoma) foram e são produzidos na tentativa de desconstruir a categoria de gênero, presente na legislação brasileira sobre a violência contra as mulheres - conhecida como Maria da Penha - n.11.340 / 2006. Assim, inspirados nas inovações desta lei, os autores questionam as possibilidades de experiências menos precárias possíveis, em especial, para os agentes sociais que são considerados para o/e pelo Estado como algo desprezível, como abjetos.

Palavras-chave: gênero, violência, legislação 


\section{Education and Rights to (In)Humans? Challenges and Reflections about Dilemmas LGBT People go Through in the Face of the Brazilian Legal Discourse}

\author{
Educación y Derechos para (In) \\ Humanos? Desafios y Reflexiones \\ Sobre los Dilemas de LGBT's Frente al \\ Discurso Juridico Brasileño
}

\section{Abstract}

This article is the result of research and dialogues on education and human rights between the authors whose starting point was their incursions into studies on gender and sexuality. All the movements outlined here (in the meaning given by Deleuze and Guatari to rizoma) were and are produced in the attempt to de-construct the category of gender, include in the Brazilian legislation about violence against women - known as Maria da Penha Act - No. 11340 / 2006. Thus, inspired by the innovations brought by such act of law, the authors question the possibility of experiences less precarious as possible, especially, for the social agents who are considered for and by the State as something despicable and abject.

Key words: gender; violence; legislation

\section{Resumén}

Este artículo es el resultado de la investigación y el diálogo sobre la educación y los derechos humanos entre los autores considerando sus incursiones en los estudios de género y sexualidad. Todos los movimientos delineados (en el sentido deleuziano/guattariano para rizoma) fueran y son producidos en un intento de deconstruir la categoría de género, presente en la legislación brasileña sobre la violencia contra las mujeres- conocida como Maria da Peña- n.11.340/2006. Así, inspirada en las innovaciones de esta ley, los autores cuestionan las posibilidades de la experiencia menos precaria que sea posible, especialmente para los agentes sociales que se consideran para el estado como abjetos.

Palabras clave: género, violência, legislación. 
O presente artigo é resultado tanto de palestras ministradas desde 2008 na cidade de Dourados/MS, quanto do desenvolvimento de projetos de extensão e de pesquisa com foco em educação e direitos humanos. Quanto aos de extensão, cabe mencionar o intitulado: "Acesso à justiça e conscientização quanto à violência doméstica", que capacitou mais de cem pessoas através de três oficinas, todas voltadas à Lei Maria da Penha e ao acesso à justiça por parte das chamadas minorias de direitos, bem como "Fins de tarde em meio à diversidade: na sala com as travestis". No tocante aos projetos de pesquisa registramos "Maiorias que são minorias, invisíveis que (não) são dizíveis: etnografias sobre sujeitos à margem dos discursos dominantes".2

Assim, a bricolagem que aqui faremos articulará as principais inquietações que suscitamos nestes diferentes momentos, cujo ponto em comum talvez seja a importância de apreendermos e replicarmos o conceito de gênero da forma mais ampliada possível, em especial, quando nossas ações mediadas por tal categoria caracterizam-se como discursos de autoridade e/ou de competência.

Para tanto, o artigo encontra-se dividido em quatro partes interligadas entre si. Iniciamos pincelando a importância da Lei Maria da Penha quanto a um de seus grandes méritos, qual seja: o de trazer em seu corpo de maneira inédita em termos legislativos o termo gênero. Porém, esperamos deixar claro que dependendo da maneira como o gênero é compreendido, de mérito ele se transforma em armadiIha, criando uma série de impasses e dilemas.

Em seguida trataremos sucintamente da categoria analítica do gênero, portanto de um de seus conceitos e da sua distinção em relação aos termos sexo e sexualidade. Como veremos, tal diferenciação torna-se imprescindível ao falarmos de acesso à justiça por parte dos humanos e inumanos que compõem a sigla LBGT.

Em um terceiro momento, retomaremos a Lei Maria da Penha e outras situações jurídico-legais, como possíveis exemplos para articular e pensar questões contemporâneas sobre o gênero no Judiciário, incluindo as críticas feitas às suas concepções restritas.
Na conclusão, sugeriremos aos leitores que somente uma visão ampliada do que vem a se entender por gênero poderá retirar determinados sujeitos da condição de inumanidade. Seguindo este raciocínio, na condição de inumanos ou de assujeitados não há que se falar de acesso a direitos ou de quaisquer visibilidades políticas, mas, talvez, somente há que se falar em ilustrações de violências simbólicas.

\section{I.}

A lei 11.340/2006, também conhecida como Lei Maria da Penha, trata das violências domésticas praticadas contra as mulheres, e de certa forma é elogiada por ter remediado, em tese (CRUZ et al, 2008), a maneira banal como o Estado via tal problema ${ }^{3}$. Aliás, fazendo nossas as palavras da socióloga Eva Blay (2008), as violências contra as mulheres, das quais a violência doméstica é uma parcela ou nuance, devem ser enfrentadas como uma questão de saúde pública. Ou seja, para além de um nível eminentemente jurídico, a violência de gênero precisa ser encarada sob o ponto de vista sociológico e, nesse sentido, as estratégias de enfrentamento precisam ser articuladas para além das políticas de punição. Em nosso entender, tanto o gênero quanto os processos de violência (tais como a violência contra mulher, bem como contra LGBTs) estão imbricados em relações de poder e imaginários socialmente estabelecidos que naturalizam as diferenças entre homens e mulheres, tornando tais diferenças como princípio de estruturação das relações sociais.

Um dos grandes avanços desta lei foi o de trazer em seu conteúdo o termo gênero (no artigo quinto) e de vinculá-lo à caracterização de todas as formas de violências domésticas praticadas contra as mulheres que não se resumem à agressão física, como a violência psicológica e a moral, ambas, definidas em seu artigo sétimo.

Todavia, inspirada novamente na obra de Eva Blay (idem), acrescentamos que não podemos focar a questão da violência contra as mulheres apenas nesta parcela representativa que é a violência doméstica, portanto, praticada por conhecidos. Ao fazê-lo, acabamos por obscurecer a 
cultura de violência na qual somos introduzidos desde que nascemos enquanto brasileiros, bem como, obscurecemos o preocupante número de feminicídios praticados contra as mulheres por desconhecidos que não mantêm com elas relações domésticas. Além dos inúmeros tipos e graus de violências a que as mulheres estão cotidianamente submetidas na dimensão física, há ainda outras violações que nem sempre são entendidas socialmente enquanto tais, por mais que constem no artigo $7^{\circ}$ da Lei Maria da Penha. A título de exemplo, ressaltamos a desigualdade de oportunidades e tratamento, assédio moral, piadas, xingamentos, etc. Portanto, para além da violência física que, em nosso ponto de vista, pode ser entendida como apenas a ponta do iceberg, há a preponderância da violência simbólica por vezes mais violenta e atroz, pois constituída de intrincadas relações de poder socialmente compartilhadas e dissimuladas.

Assim, observa-se que a Lei Maria da Penha visibiliza a categoria gênero, muito embora não a conceitue, e explicita que além dos homens, as mulheres também podem ser consideradas agressoras, independentemente da orientação sexual. Mas, aonde desejamos chegar com estes lembretes acerca de quem podem ser agressores e vítimas para a Lei Maria da Penha? À assertiva de que essa legislação deve resguardar todas as mulheres que assim se veem sob uma perspectiva ampliada de gênero, para além da imposição do que vem a ser definido como sexo em nossa sociedade, que assim como o gênero também é uma construção social.

Sob este raciocínio, todas as políticas públicas que decorrem de implementações que a lei Maria da Penha ainda espera para sua maior efetividade na erradicação desta epidemia, devem ser realizadas sob esta perspectiva, bem como, todas as adequações da citada lei e de outras pelos operadores do direito a casos concretos devem ser feitas sob uma perspectiva ampliada de gênero, quando essa categoria é acionada implícita ou explicitamente.

Para que esta nossa hipótese fique suficientemente costurada, partimos para um dos possíveis conceitos da categoria analítica gênero, levando em consideração o breve retrospecto no qual o termo gênero emergiu.
A partir da década de 80 do século passado, ou como diz a própria historiadora Joan Scott, "muito recentemente" as teóricas de diferentes campos do conhecimento que estudavam as mulheres, e os processos sociais e históricos que perpetuavam (e perpetuam) a desigualdade entre os sexos, cunharam a tais o rótulo de estudos de "gênero". Diga-se de passagem, ao se utilizar o termo "gênero", uma reavaliação crítica dos métodos e da compreensão do mesmo como não pautado apenas nas descrições das relações entre os sexos, caracterizaria o novo horizonte das pesquisas desenvolvidas pelas teóricas feministas ${ }^{5}$.

Assim, enquanto possível conceito de gênero, remetemo-nos àquele para lá de referenciado por todos os estudiosos de gênero, que é de autoria da historiadora Joan Scott. Diz ela, o gênero:

(...) rejeita explicitamente explicações biológicas como aquelas que encontram um denominador comum, para diversas formas de subordinação, no fato de que as mulheres têm as crianças e que os homens têm uma força muscular superior. O gênero torna-se, antes, uma maneira de indicar "construções sociais"criação inteiramente social de idéias sobre os papéis adequados aos homens e às mulheres. É uma maneira de se referir às origens exclusivamente sociais das identidades subjetivas dos homens e das mulheres. O gênero é, segundo esta definição, uma categoria social imposta sobre um corpo sexuado. Apesar do fato dos(as) pesquisadores(as) reconhecerem as conexões entre o sexo e o que os sociólogos da família chamaram de "papéis sexuais", aqueles(as) não colocam entre os dois uma relação simples ou direta. O uso do "gênero" coloca a ênfase sobre todo o sistema de relações que pode incluir o sexo, mas que não é diretamente determinado pelo sexo nem determina diretamente a sexualidade (SCOTT, 2009, s/p ${ }^{6}$ ). (negritos nossos).

Neste sentido, não podemos perder de vista três elementos constitutivos deste conceito de gênero proposto por Joan Scott.

Quanto ao primeiro elemento, vê-se que produzimos representações sobre o corpo biológico ou sexuado 
(homem com pênis e mulher com vagina ${ }^{7}$ ) por meio de simbologias que acabam por reiterar tanto a polaridade entre os universos masculinos e femininos quanto as suas assimetrias naturalizadoras. Essas, por sua vez, equivalem às representações que recaem sobre os corpos sexuados e, que, cada um de nós contribui em nossos cotidianos na e para a sua (re)produção e que não podemos esquecer que são contextualizadas e eminentemente sociais.

Para que visualizemos estas convenções sociais, nunca é demais pensarmos em exemplos tão corriqueiros e concretos, que mencionamos em forma de questionamentos. Quem disse que cor de menino é azul e de menina é rosa? Quem disse que menino brinca de bola e menina de boneca? Sempre foi assim e sempre será? Não, trata-se de convenções sociais, bem localizadas e contextualizadas. Além disso, como ignorar o papel das expectativas sobre a "descoberta" do sexo do bebê e como esse ato performativo ${ }^{8}$ cria uma determinada identidade ao futuro sujeito social que o localizará como pertencendo a um universo propriamente masculino e feminino com todas as implicações dai advindas? Trata-se, assim, de um sistema de "representações" que separa mundos, "papéis" e, consequentemente, cria e naturaliza invisibilidades e violências. Retomemos os elementos constitutivos do conceito de gênero proposto por Joan Scott.

No que diz respeito ao segundo elemento, observa-se que estas simbologias estão ligadas a significados produzidos pelos diferentes discursos que nos constituem enquanto sujeitos sociais. Destacamos alguns destes poderosos discursos que nos fazem apreender certos significados culturais como sendo "naturalizados". São eles: educacional, religioso, científico (incluindo o médico) e o jurídico. Todos, aliás, que podem perpetuar "violências simbólicas" a partir de vetores como os de gênero, de raça, de geração, de classe social e de etnia. Se não, vejamos com os próprios dizeres de Pierre Bourdieu:

A violência simbólica se institui por intermédio da adesão que o dominado não pode deixar de conceder ao dominante (e, portanto, à dominação) quando ele não dispõe, para pensá-la e para se pensar, ou melhor, para pensar sua rela- ção com ele, mais que de instrumentos de conhecimento que ambos têm em comum e que, não sendo mais que a forma incorporada da relação de dominação, fazem esta relação ser vista como natural; ou, em outros termos, quando os esquemas que ele põe em ação para se ver $\mathrm{e}$ se avaliar, ou para ver e avaliar os dominantes (elevado/baixo, masculino/feminino, branco/ negro, etc), resultam da incorporação de classificações, assim naturalizadas, de que seu ser social é produto. (BOURDIEU, 1999, p.47).

Ou seja, no processo de dominação, os dispositivos responsáveis pela internalização dos modelos de representação social precisam ser naturalizados pelos sujeitos sociais para que sua eficácia seja efetiva. Nesse jogo, a dissimulação da violência e dos sistemas de poder é fundamental. Assim é que podemos compreender uma série de discursos referidos às relações de gênero na esfera do social, e que os atrelam a um ideal de"normalidade"ligada à "tradição", criando uma oposição deliberada. Embora nem sempre consciente, com relação aos papéis de gênero no que tange às diferenças entre homens e muIheres e ao lugar do feminino na sociedade, tais discursos binários produzem e reproduzem alguns aforismos: "É assim mesmo"; "Aprendi assim"; "Fui educado/a assim"; "Sempre foi assim", etc. Na esteira deste conceito bourdiano ou a ele atrelado, pode-se pensar que a violência simbólica encontra-se de mãos dadas com os atos ou discursos de autoridade (BOURDIEU, 1998), que apresentam similitudes com aqueles ditos de competência de autoria de Marilena Chauí.

O que é o discurso competente enquanto discurso do conhecimento? Sabemos que é o discurso do especialista, proferido de um ponto determinado da hierarquia organizacional. Sabemos também que haverá tantos discursos competentes quantos lugares hierárquicos autorizados a falar e a transmitir ordens aos degraus inferiores e aos demais pontos da hierarquia que lhe forem paritários. Sabemos também que é um discurso que não se inspira em idéias e valores, mas na suposta realidade dos fatos e na suposta eficácia dos meios de ação. Enfim, também sabemos que se trata de um discurso instituído ou da ciência institucionalizada e não de um saber instituinte e inaugural 
e que, como conhecimento instituído, tem o papel de dissimular sob a capa da cientificidade a existência real da dominação. Todavia, essas determinações da linguagem competente não nos devem ocultar o fundamental, isto é, o ponto a partir do qual tais determinações se constituem. A condição para o prestígio e para a eficácia do discurso da competência como discurso do conhecimento depende da afirmação tácita e da aceitação tácita da incompetência dos homens enquanto sujeitos sociais e políticos. (...). Para que esse discurso possa ser proferido e mantido é imprescindível que não haja sujeitos, mas apenas homens reduzidos à condição de objetos sociais. (...). Essa tentativa se realiza através da competência privatizada. Invalidados como seres sociais e políticos, os homens seriam revalidados por intermédio de uma competência que Ihes diz respeito enquanto sujeitos individuais ou pessoas privadas. Ora, essa revalidação é um logro na medida em que é apenas a transferência, para o plano individual e privado, do discurso competente do conhecimento cujas regras já estão dadas pelo mundo da burocracia e da organização. Ou seja, a competência privada está submetida à mesma reificação que preside a competência do discurso do conhecimento. Basta que prestemos uma certa atenção ao modo pelo qual opera a revalidação dos indivíduos pelo conhecimento para que percebamos sua fraude. (CHAUI, 1982, p.11-12).

Assim, pensamos que o exercício da cidadania ou o acesso aos direitos inacessíveis pelas propaladas "minorias", dentre as quais se destacam as travestis, transexuais, homossexuais, bissexuais, etc., só se faz possível em termos da categoria gênero, se o uso que dela fazemos se afina com os propósitos mais ousados de sua compreensão. ${ }^{9}$ Ou seja, impõem-se a necessidade de uma compreensão tanto da importância política da categoria gênero, mas também seus limites e contradições em termos de políticas de identidades e especificidades sociais (BUTLER, 2003). Como ignorar, por exemplo, mesmo em relação às mulheres (assim categorizadas desde o nascimento pelo discurso biomédico imposto nas certidões de nascimento), marcadores sociais de diferenças que podem tornar a condição feminina ainda mais vulnerável, como: raça/ etnia, classe social, geração, etc. É assim que desembocamos, então, no último elemento que constitui, a nosso ver, o foco principal do conceito de Joan Scott.
Quanto ao terceiro elemento, destaca-se que um dos grandes desafios contemporâneos para os estudiosos do gênero baseia-se na explosão das dicotomias subentendidas e "naturalizadas" a partir da matriz sexual. Em outros dizeres, no rompimento da existência de um sujeito como pautado apenas e tão somente no binômio que se perfaz pela oposição à outra possibilidade de existência, a saber: ou se é homem, ou se é mulher.

Sob este raciocínio, o termo "gênero" foi estrategicamente escolhido pelas teóricas feministas, face à definição tomada de empréstimo da gramática, tendo em vista algumas das línguas indo-européias. Para essas, diz Joan Scott, o gênero representa tanto o masculino e o feminino veiculados pelos artigos "o" e "a" que antecedem ou sucedem certas palavras, quanto o sexo neutro ou indefinido que não se encaixa nem no "a" nem no "o". Em seus próprios dizeres:

A conexão com a gramática é ao mesmo tempo explícita e cheia de possibilidades inexploradas. Explícita, porque o uso gramatical implica em regras que decorrem da designação do masculino ou feminino; cheia de possibilidades inexploradas, porque em vários idiomas indo-europeus existe uma terceira categoria - o sexo indefinido ou neutro. Na gramática, gênero é compreendido como um meio de classificar fenômenos, um sistema de distinções socialmente acordado mais do que uma descrição objetiva de traços inerentes. Além disso, as classificações sugerem uma relação entre categorias que permite distinções ou agrupamentos separados. (SCOTT, $2009, s / p)$.

Com base neste terceiro elemento, torna-se inevitável nos debruçarmos sobre a proposta teórica de Judith Butler (2003), para quem a dicotomia sexo/gênero, até então levada à cabo pela teóricas feministas, mostra-se insustentável. A partir da noção de performatividade ligada à proposta de Austin como antes exposto - , Butler sustenta que nem o sexo nem o gênero são categorias elucidativas em si mesmas. Pelo contrário, a ideia de perenidade dos conceitos, concebidos como a priori, demonstram atos deliberados e performativos, próprios de uma metafísica da substância que tende a atribuir essencializações/substancializações tanto aos corpos quanto 
às práticas sociais em que a "coerência" e a "continuidade" são buscadas e reiteradas. Para a autora, haveria no mundo social a busca por uma finalidade (telos) dos corpos e dos desejos engendrados em normas de inteligibilidade socialmente instituídas e naturalizadas (2003, p. 38).

Assim sendo, para Butler, as coerências de gênero mostram-se como verdadeiras ficções reguladoras, haja vista, o caráter ambíguo e flutuante das identidades. Assim, ao considerar o caráter performativo tanto do gênero quanto do sexo, Butler chama a atenção para a arbitrariedade e para a insustentabilidade dos modelos que reiteram a univocidade ou coerência inequívoca entre sexo, gênero e desejo como (re)produtora e (re)produzida pela estrutura binária alicerçada na "conjunção carnal" da heteronormatividade. Em síntese, não há um sujeito a priori da ação. $\mathrm{O}$ que há é o sujeito se produzindo a partir da ação e de sua iteração/repetição posta a partir das relações sociais.

Além disso, influenciada pela perspectiva foucaultiana, que considera as relações de poder como um aspecto importante das relações sociais, Butler afirma:

Foucault observa que os sistemas jurídicos de poder produzem os sujeitos que subsequentemente passam a representar. As noções jurídicas de poder parecem regular a vida política em termos puramente negativos - isto é, por meio de limitação, proibição, regulamentação, controle e mesmo "proteção" dos indivíduos relacionados àquela estrutura política, mediante uma ação contingente e retratável de escolha. Porém, em virtude de a elas estarem condicionados, os sujeitos regulados por tais estruturas são formados, definidos e reproduzidos de acordo com as exigências delas. Se esta análise é correta, a formação jurídica da linguagem e da política que representa as mulheres como "o sujeito" do feminismo é em si mesma uma formação discursiva e efeito de uma dada versão da política representacional. (BUTLER, 2003, p.18-19).

Vê-se que este discurso de competência denominado de jurídico é um dos principais responsáveis pela produção dos sujeitos sociais que se representam e passam a inferir representações, através de recursos que não extrapolam as estruturas por meio das quais são representados. Afi- nal de contas, numa sociedade baseada na letra, o que não está definido em termos jurídicos-normativos, acaba por tornar-se não-ser, não existente, e então abjeto/inumano. Daí a necessidade ou o desafio de grupos minoritários e vulneráveis acessando uma aplicação sob outros olhares de dispositivos legais disponíveis, e quando indisponíveis na luta pela sua produção. Por outro lado, nem sempre o acesso ao reconhecimento goza de legitimidade e efetividade. Eis um dos fundamentos básicos da própria noção de "violência simbólica". E, se focarmos na categoria gênero, o seu problema reside na imposição restritiva, impositiva e negativa de sermos homens ou sermos mulheres. O ambíguo e/ou o indefinido não é representado, e, então, não existe para o universo do direito. Trocando em miúdos, continua Butler:

A noção binária de masculino/feminino constitui não só a estrutura exclusiva em que essa especificidade pode ser reconhecida, mas de todo modo a "especificidade" do feminino é mais uma vez totalmente descontextualizada, analítica e politicamente separada da constituição de classe, raça, etnia e outros eixos de relações de poder, os quais tanto constituem a"identidade" como tornam equívoca a noção singular de identidade.

É minha sugestão que as supostas universalidade e unidade do sujeito do feminismo são de fato minadas pelas restrições do discurso representacional em que funcionam. (idem, p.21).

Portanto, se em termos básicos e superficiais o gênero é o que agregamos ao corpo sexuado, e é por essência mutável e representacional, mas não somente redutível aos binarismos ditados pelo discurso legal, jurídico e médico, cremos que a partir destes dados devemos entender também quais são as características que circundam o que vem a se produzir discursivamente enquanto ser homem e ser mulher em nossa sociedade. Isto é, quais são os parâmetros definidores do sexo e do gênero para nós ocidentais.

Para tanto recorremos a Michel Foucault (1978, 2007, 2004), que problematiza como certas verdades são produzidas por determinados poderes/saberes discursivos. Como não pensar a naturalização das relações de gêne- 
ro, a violência contra a mulher, contra os LGBTs e todas as ideologias que as sustentam a não ser como dispositivos engendrados em discursividades, saberes e práticas que servem para instalar e reiterar um regime normativo? Um normal que sinaliza para a capacidade de produção de normas contrariamente ao patológico, tomado como tal pela incapacidade de produzir normas em um dado contexto social e histórico.

II.

Michel Foucault publicou em 1978 as memórias e os diários de Herculine Barbin. Quem era Herculine Barbin também conhecida como Alexina? Em poucas palavras, Alexina vivia em um convento francês no período compreendido entre 1860 e 1870, com um estilo gracioso, um pouco pomposo e em desuso. Vivia em um universo eminentemente feminino. Eis que é nesta época, um período que reputamos como de "mutação", que a Medicina (incluindo a Psiquiatria) enquanto um discurso autorizado pelo Estado, e com um poder proeminente, passa a definir os sujeitos de maneira distinta daquela anteriormente válida como "normal", a saber: desta época em diante a verdade sobre os sujeitos passa pelo sexo verdadeiro.

Vamos aos dizeres de Foucault:

\begin{abstract}
É no sexo que devemos procurar as verdades mais secretas e profundas do indivíduo; que é nele que se pode melhor descobrir o que ele é e aquilo que o determina; e se durante séculos acreditamos que fosse necessário esconder as coisas do sexo porque eram vergonhosas, sabemos agora que é o próprio sexo que esconde as partes mais secretas do indivíduo: a estrutura de seus fantasmas, as raízes de seu eu, as formas de sua relação com o real. No fundo do sexo, está a verdade (FOUCAULT, 1982, p.4).
\end{abstract}

Se antes deste período, até o século XVIII, o que existia era o modelo do sexo único enquanto dominante (TONELI, 2008, p.63), a partir de meados do século XIX, com o nascimento da clínica, os hospitais passaram de grandes entulhos ou depósitos de indigentes, leprosos e demais inumanos, para um grande espaço destinado ao aprendizado da anatomia. Não esqueçamos que é muito recente, há apenas alguns séculos que a gramática das entranhas de nosso corpo humano passou a ser construída. Assim não é por acaso que para Foucault, o poder disciplinar, estabelecido a partir do século XVIII, adota como estratégia privilegiada o olhar. Afinal, é por meio do olhar que ocorre o esquadrinhamento, a vigilância, a mensuração, a quantificação, as diferenciações entre sujeitos, o estabelecimento de espacialidades, etc. Sobre a soberania do olhar médico Foucault afirma: "(...) dirige-se ao que há de visível na doença, mas a partir do doente, que oculta este visível, mostrando-o; consequentemente, para conhecer, ele deve reconhecer." (FOUCAULT, 2008, p. 8-9). Nesse jogo do ver que esquadrinha e rotula, coração, pulmão, cérebro, útero, e outros tantos órgãos passaram a ser nomeados. O que (não) dizer dos sujeitos, suas identidades e práticas? Tudo para justificar o inevitável e a força motriz da medicina: o retardamento da morte e a manipulação dos corpos. Da mesma forma, outras disciplinas como a psicologia e a psicanálise não escapam a esta produção dicotomizada entre os sexos com certas nuances que as particularizam. Como bem coloca Maria Juracy Filgueiras Toneli:

Ao longo do século XIX, o desenvolvimento da pesquisa biológica continua marcado pela fisiologia da reprodução. Por outro lado, a retomada da diferença mostra-se, sobretudo, na tematização da condição normal da sexualidade e de sua degeneração. A Psicologia surge aqui, direcionando-se para a psicofísica e para pesquisas sobre as reações dos sistemas sensoriais - incluindo a excitação sexual e as chamadas "respostas sexuais". O que se pode observar de diferenciação com relação ao século anterior é uma maior separação ente a sexualidade e a reprodução. No entanto, por outra via, há uma aproximação maior da sexualidade com a moralidade. Nem mesmo a Psicanálise escapa a esta aproximação, uma vez que, embora tenha promovido rupturas com o pensamento hegemônico que via as crianças como assexuadas e tenha redefinido a própria noção de sexualidade colocando-a em posição central no desenvolvimento do psiquismo, a escola freudiana manteve-se apegada à moralidade vitoriana, inclusive no que diz respeito à orientação sexual. (TONELI, 2008, p.63-64). 
Mas voltemos a Herculine Barbin. Por que o diário de uma suicida interessou Michel Foucault? Tratava-se de uma hermafrodita que era vista como uma mulher e aceita socialmente como tal até meados de 1860, e que por uma imposição do conhecimento científico foi obrigada por uma ordem judicial a escolher entre um dos dois únicos sexos disponíveis a partir daquela data. A medicina submeteu-a a cirurgia. Dito de outra forma: ela e/ou ele não poderia mais viver na indefinição, pois o neutro não mais seria concebível enquanto vivível, pensável e, portanto, existente. Talvez, não por acaso, ela se suicidou, porque já estava morta socialmente.

As memórias de sua vida, Alexina escreveu quando já havia sido descoberta e estabelecida sua nova identidade. Sua "verdadeira" e "definitiva" identidade. Mas é óbvio que não é do ponto de vista desse sexo enfim encontrado ou reeencontrado que ela as escreve. Não é o homem que fala, tentando relembrar as sensações e a vida de quando não era ainda "ele-mesmo". Quando Alexina redige suas memórias, não está longe do seu suicídio; ela tem sempre para ela mesma um sexo incerto; mas é privada das delícias que experimentava em não ter esse sexo, ou em não ter totalmente o mesmo sexo que tinham aquelas com as quais vivia, amava e desejava tanto. E o que ela evoca do seu passado é o limbo feliz de uma não-identidade, que protegia paradoxalmente a vida dentro daquelas sociedades fechadas, estreitas e calorosas, onde se tem a estranha felicidade, ao mesmo tempo, obrigatória e interdita, de conhecer apenas um único sexo. (FOUCAULT, 1982, p.6-7).

Feitas estas considerações, sugerimos que somente são humanos ${ }^{10}$ aqueles que nascem de uma mulher e não de outra fêmea mamífero, e que tais humanos somente podem ser homens ou mulheres, mesmo que para tanto a medicina deva fazer a opção, como no caso das crianças intersexuais ${ }^{11}$ (as antigas hermafroditas). Assim, apenas os humanos que são homens ou mulheres, poderão, a nosso ver, sob o raciocínio hoje vigente, exercer suas cidadanias ao exigir do Estado a garantia de seus direitos tidos como humanos. Ou seja, para além da necessidade de existir como ser é necessário existir socialmente e sob os ditames do estatuto de cidadania, juridicamente estabelecido rimando com humanidade. Aliás, o exer- cício da cidadania se faz no embate com o discurso de competência do direito e (in)diretamente com o da medicina. Então, quando em campanha publicitária há anos atrás o governo federal brasileiro lançou a propaganda evocando o slogan que para ter direitos humanos, basta ser humano, há que se levar em conta que somente os humanos é que acessam os direitos ditos humanos. Algo óbvio? Talvez, mas pouco explorado, partindo-se do pressuposto de que nem todos os sujeitos sociais são considerados humanos para o discurso do direito. Afinal o que é o humano? Quais são os critérios para ser considerado enquanto tal? Trata-se de uma condição que pode ser atribuída a qualquer sujeito? Ou haveriam determinados pressupostos requeridos para tal? Que pressupostos seriam esses? Quem os estabelece? Sob quais critérios? Quem fica "inominável" numa condição de abjeção? Eis a coerência entre sexo, gênero e desejo, considerando raça, etnia e classe social. Quanto mais pobre, negro/a, indígena e não heterossexual o sujeito assujeitado se (re) produz, mais inumano e menos humano é considerado pelo Estado. Eis os tentáculos ou facetas da face perversa do racismo de Estado (FOUCAULT, 2010).

Desta forma, resta um último esclarecimento em relação aos breves apontamentos sobre o conceito de gênero para que possamos compreender a importância desta categoria junto aos discursos de autoridade/competência, responsáveis também pela feitura das políticas públicas que se estabelecem, em especial, após a Constituição de 1988 com e no diálogo junto aos movimentos sociais. Trata-se do significado da expressão orientação sexual. Aliás, outra temática ou categoria teórica que não se confunde nem com gênero, nem com sexo. Faremos estes esclarecimentos tendo como parâmetro a sigla LGBT e as confusões que a partir dela são produzidas no tocante às identidades de gênero, de sexo e em relação à sexualidade.

O que significa a letra "L" e a letra "G"? Talvez estas duas letras sejam as mais conhecidas. $L$ refere-se às lésbicas que são aquelas mulheres que se sentem atraídas por mulheres e vivem relações eróticas com mulheres, e G refere-se aos gays que são homens que se sentem atraídos por homens e vivem relações eróticas com homens. 
Notem que antes de se sentirem e de viverem relações com pessoas do mesmo sexo, gays e lésbicas são, respectivamente, homens e mulheres. Tanto assim o é que a inversão de GLBT para LGBT desde junho de 2008 no Brasil ocorreu face às demandas de rompimento das relações de subordinação e invisibilidade vividas pelas mulheres lésbicas com os homens gays em meio à militância homossexual.

Sob este raciocínio, ao sublinhar que lésbicas e gays são antes de tudo mulheres e homens, apontamos para o fato da sexualidade ser um adjetivo em suas vidas, e não o elemento constitutivo de suas existências enquanto sujeitos. Com muitas ressalvas, estendemos o mesmo raciocínio para os antigos " $S$ " - simpatizantes - que foram incorporados na sigla LGBT como os "B" de bissexuais, isto é, aqueles homens ou mulheres que desejam e se relacionam sexual-afetivamente tanto com homens quanto com mulheres. Por que as ressalvas? Porque esta situação de ambigüidade quanto à escolha erótica do sujeito bissexual também causa rejeição, muito maior, a nosso ver, do que aquela desfrutada por homossexuais - sejam eles gays ou lésbicas. Afinal, como diria a antropóloga Mary Douglas (1976), as situações de liminaridade - daqueles que estão na fronteira de uma dupla condição ou co-existência, faz com que todos os demais que fazem suas escolhas por ser uma coisa ou outra signifiquem estes sujeitos como impuros ou sujos.

De qualquer forma, todas estas três condições (Ls, Gs, e Bs) que refletem a sexualidade de nós sujeitos, ao lado da aprovadíssima heterossexualidade - que são os homens e as mulheres que vivem eroticamente e de preferência maritalmente com o sexo oposto - desfrutam da condição de humanidade.

Diferentemente do que sugere o antropólogo Luiz Mott (2003) em relação aos motivos que fazem dos homossexuais os mais odiados dentre todos os grupos minoritários em nossa sociedade, cremos que as discriminações sofridas na pele por cada um dos componentes da letra " $T$ ", no e para o universo jurídico e legal são piores do que aquelas sofridas pelos homossexuais, quiçá se à condição de travestis e de transexuais, acrescentarmos, por exemplo, os vetores de etnia e de raça ${ }^{12}$. E mais: veremos daqui a pouco que mesmo entre aqueles que vivem guarnecidos sob o "T" (o grande "tesão") há significativas diferenças. Perguntamo-nos: quem são estes que se escondem ou são escondidos por detrás do "T"? Trata-se, em especial, das travestis e dos transexuais. Eles são sinônimos? Pensamos que não e para reforçar este argumento, remetemos o leitor aos esclarecimentos da antropóloga e psicanalista Elisabeth Zambrano:

É muito comum homossexuais, travestis e transexuais serem percebidos como fazendo parte de um mesmo grupo, numa confusão entre a orientação sexual (homossexualidade, heterossexualidade e bisssexualidade) e as "identidades de gênero" (homens masculinos, mulheres femininas, travestis, transexuais femininos e masculinos, entre outras).

Todos os indivíduos que reivindicam um gênero que não apoiado no seu sexo podem ser chamados de "transgênero". Estariam incluídos aí, além de transexuais que realizaram cirurgia de troca de sexo, travestis que reconhecem seu sexo biológico, mas têm o seu gênero identificado como feminino; travestis que dizem pertencer a ambos os sexos/gêneros e transexuais masculinos e femininos que se percebem como homens ou mulheres mas não querem fazer cirurgia. A classificação de suas práticas sexuais como homo ou heterossexuais estará na dependência da categoria que estiver sendo considerada pelo indivíduo como a definidora de sua identidade. (apud RIOS, 2008, p.21-22).

Tomando como consensual que as travestis são aquelas que têm pênis e desfrutam do gozo - em sentido amplo - por detê-lo; e que os/as transexuais cirurgiados/as são aqueles que nasceram com um sexo imposto pelo discurso médico e jurídico, e que ao longo de suas trajetórias de vida modificam-no face às angústias que podem levá-los ao suicídio, uma vez que se vêem antes da cirurgia enquanto "erros de natureza" (Idem, 2008); arriscamos duas sugestões analíticas a partir das quais rumamos para a sinalização de quem é que são socialmente tratados como os inumanos nesta sigla, LGBT, e, então, despidos, a nosso ver, de quaisquer garantias e direitos desfrutados apenas pelos "humanos", inclusive perante a lei Maria da Penha. Assim, nos parece que estes inuma- 
nos são produtos também de uma visão não ampliada do que se entende por gênero, e, então arcam com as conseqüências de violências simbólicas advindas dos discursos de autoridade. Dito de outro modo, lésbicas, gays, bissexuais podem, ao permanecer no "armário", sendo "discretos/as", ou mesmo sendo assumido/as; continuar na condição de humanos (OLIVEIRA, 2014), e as/os transexuais podem passar por meio da transgenitalização de uma condição de "indefinição" anatômica e identitária para uma condição de "definição", tornando-se homens ou mulheres. As travestis por sua vez, ao não se inserirem dentro da lógica da "discrição" e da "definição", borram as normas de gênero e, deste modo, tem na abjeção, enquanto negação de humanidade, a condição "sine qua non" de seu estar no mundo social. Trata-se de uma condição liminar que nos permite problematizar tanto as arbitrariedades de um regime de verdade quanto os modelos que os constituem. Em nosso entender, ao questionarem as normas convencionais de gênero por meio de sua performatividade, as travestis, por meio de sua lógica deliberada de "parecer" $\mathrm{e}$ "sentir-se" mulher (BENEDETTI, 2005) colocam em xeque as lógicas das definições essencializadas/substancializadoras e como consequência, passam a sofrer da condição de desviantes (BECKER, 2008) e abjetos.

III.

Passamos às antes citadas sugestões, e com elas trazemos alguns exemplos de nossos tribunais quanto ao tratamento da questão de gênero frente à Lei Maria da Penha e outras legislações.

Em primeiro lugar, pode-se inferir que os/as transexuais pós cirurgiados, muito embora sejam rotulados pelo discurso médico e outros discursos de autoridade como "doentes", passam a desfrutar em alguns dos nossos contextos sociais - incluo o jurídico - da aceitação de suas condições de serem mulheres ou homens.

Como exemplo, mencionamos o parecer da procuradora de justiça do tribunal da Bahia, Regina Helena Ramos Reis (2008), que aos 11 dias do mês de outubro de 2006, concedeu o direito de uma transexual cirurgiada modifi- car seu nome e seu sexo em seus documentos pessoais. Além destes direitos, o parecer da promotora vinculou a mudança de nome e de sexo da transexual à garantia dela - enquanto mulher - poder se casar com um homem, como toda e qualquer mulher heterossexual, que desde o nascimento portou fenótipos e genótipos que a caracterizam perante o discurso médico enquanto uma mulher. Ou seja, eles e elas que trocaram de sexo e aos poucos de documentos, perante o Judiciário, lentamente são considerados em algumas situações enquanto "humanos", e, em decorrência disso, gozam dos mesmos direitos civis que os heterossexuais.

$\mathrm{Na}$ esteira deste exemplo, citamos outro documento jurídico chamado de "doutrina" que diz respeito à própria lei Maria da Penha e, que em seu conteúdo aborda se os sujeitos transexuais podem ou não ser resguardados por ela. Trata-se das interpretações dos juristas Luiz Antônio de Souza e Vitor Frederico Kümpel (2008), constante na obra "Violência doméstica e familiar contra a mulher: Lei 11.340/2006".

Ambos os juristas definem quem são os "sujeitos passivos", isto é, aqueles que podem sofrer perante a teoria do direito penal brasileiro os crimes assim classificados em lei, e, neste caso analisado, podem sofrer as diferentes violências domésticas enumeradas no artigo sétimo da Lei Maria da Penha. Afirmam eles que: "o sujeito passivo é exclusivamente a mulher nas suas relações individuais, coletivas e difusas. E o que identifica a mulher é o critério hormonal". (Idem, p.84).

Observa-se que esta definição torna coerente o que os doutrinadores entendem como mulher, e, então sujeito passível de sofrer violência doméstica, quando em outro momento da obra definem que:

Diante do amplo espectro da lei até relações protegidas pelo biodireito passam a estar tuteladas, de maneira que, se o transexual fizer cirurgia modificativa de sexo e passar a ser considerado mulher no registro civil, terá efetiva proteção. (Ibidem, p.81).

Percebam que os dois exemplos retirados do discurso legitimado do Direito e da Medicina, trazem para o universo 
restrito do conceito de gênero - enquanto binário e excludente do ser homem ou do ser mulher - sujeitos que estavam classificados no entremeio, visto que não eram nem mulheres, nem homens, mas os dois. Essa é a conceituação de gênero que deve ser questionada, porque perpetua violências simbólicas sobre aqueles que, por exemplo, apresentam em suas existências mundanas características que singularizam ao mesmo tempo o que é ser homem e o que é ser mulher, e não ser homem ou ser mulher.

Trazemos para reforçar nossa reflexão, um dos maiores teóricos e operadores do direito da atualidade, Roger Raupp Rios, juiz federal do Tribunal Regional Federal (TRF) da 4a região, em um de seus julgamentos produzido em 14 de agosto de 2007, no qual condenou a União a incluir na Tabela de Procedimentos remunerados pelo Sistema Único de Saúde (SUS) as cirurgias de transgenitalização, bem como, condenou a União a promover que as citadas intervenções médicas sejam feitas pelo SUS.

Ao discorrer sobre o gênero e as identidades de gênero, o magistrado acrescenta que os direitos de troca de nome e de sexo nos diversos documentos que nos tornam cidadãos, não podem ser reduzidos àquelas transexuais que se submetem à cirurgia. Acompanhemos suas explicações à luz de uma concepção ampliada do que vem a ser gênero. Diz ele:

Uma solução que se fundamente exclusivamente numa concepção biomédica e limitada do fenômeno da transexualidade conduz não-só à limitação da esfera de auto-determinação de indivíduos "heterossexuais normais" (homens heterossexuais dotados de modos mais delicados e temperamento mais sensível, por exemplo, são excluídos em testes psicotécnicos para cargos públicos policiais por não atenderem à "escala de heterossexualidade", como tive oportunidade de constatar em processo judicial) e de transexuais (que, como veremos, podem pleitear judicialmente, já tendo obtido sucesso, alteração de nome e registro civil sem submeter-se à cirurgia de transgenitalização), como também produz e legitima graves violações de direitos fundamentais de mulheres, travestis e homossexuais. (RIOS, $2008, s / p)$. (grifos do original e nossos)
Em outro momento de reflexão (2003), Rios aprofunda teoricamente as diferenças de interpretações e aplicações por parte dos operadores do direito, da categoria jurídica denominada de "princípio da igualdade", cujas conseqüências práticas desembocam nestas "graves violações de direitos fundamentais de mulheres, travestis e homossexuais". Para iniciar esta discussão, o mencionado autor reporta-se a Michel Foucault da História da Sexualidade, Volume I, com o intuito de destacar que o filósofo:

Afirma que a pessoa pode sobreviver, desde que não apareça, ou seja, desde que se coadune a esse parâmetro.

As mulheres, os negros e os homossexuais terão direitos desde que se comportem e aceitem todas as visões do mundo, as posturas e as condutas dos homens brancos heterossexuais. (Idem, p. 157).

A partir da citada assertiva, Rios sugere que os direitos concedidos às mulheres, aos negros e aos homossexuais em que para tanto seja questionado ou desconstruído o padrão referencial (redundâncias a parte) hegemônico do homem branco e heterossexual, não deixa de ser um avanço, mas equivale à adequação do princípio da igualdade como algo antidiscriminatório.

Portanto, e sem maiores delongas - por mais que esta questão merecesse maiores aprofundamentos, o efetivo avanço viria e vem quando o princípio da igualdade é interpretado e analisado juntamente com o princípio da anti-subjugação, que, ao dar suas mãos também ao princípio da dignidade humana, acaba por conferir igual tratamento às pessoas independentemente de suas condições. Caso contrário, tudo o que é estendido às ditas minorias, sob o slogan de concessão de efetivos direitos, acaba por estar revestido de uma "intolerância indulgente e heterossexista" (Ibidem, 158).

Retomemos as sugestões analíticas por nós propostas, mais especificamente no que tange às travestis. Partimos, portanto, do pressuposto de que elas são aquelas tidas cotidianamente como inumanas. Situação, aliás, vivida por Herculine Barbin, a "hermafrodita" descrita e analisada por Michel Foucault que se suicidou após ser obrigada a optar por um sexo, afinal, tiraram dela o direi- 
to de poder ser ela mesma e gozar dos prazeres da vida com um sexo indefinido.

Para ilustrar esta inumanidade, e, então a "visibilidade" das travestis no contexto jurídico legal, transcrevemos abaixo um dos relatos constante no processo criminal $\mathrm{n}$. 2008.015632-5, julgado em grau de recurso pelo Tribunal de Justiça de Santa Catarina (TJSC). ${ }^{13}$ Antes, porém, esclarecemos que ao digitar a palavra chave "travestis" no site do mencionado tribunal de justiça, ${ }^{14} \mathrm{dez}$ foram os processos acessados e todos da área criminal, em meio aos quais, as travestis consta(va)m ora como vítimas, ora como rés, ora como paisagens ou décors das cenas dos crimes ocorridos em locais de prostituição. Voltamos ao relatório do processo de $n^{\circ} 2008.015632-5$ do TJSC (DA SILVA, 2009, p.01-02):

No dia 12 de maio de 2002, por volta das $23 \mathrm{~h}$ e $30 \mathrm{~min}$, o denunciado, a fim de satisfazer sua lascívia, dirigiu-se até o Trevo da Jucasa, naquela comarca, local popularmente conhecido como ponto de travestis.

Assim é que, chegando ao local, abordou Alessandro Falcheti, conhecido como "Michele", propondo encontro sexual, o que não ocorreu em face do desacordo sobre o preço a ser pago.

Insaciável em seu desejo de relacionar-se sexualmente com um travesti, o denunciado, mais adiante, abordou a vítima Marcelo Anderson Paim, conhecido por "Valéria", tendo ambos deixado o local no veículo GM/Corsa, ST/CAR/ Camionete, placas MBI-7876, de propriedade do denunciado.

Terminado o encontro amoroso, algum tempo depois, o veículo retornou ao local (Trevo da Jucasa), tendo o denunciado o estacionado sob umas árvores ali existentes, ocasião em que ele, acusado, recusou-se a pagar o preço pelo programa sexual realizado, iniciando-se, assim, discussão entre ele e a vítima Marcelo que, visando a satisfazer sua pretensão, apossou-se dos óculos do denunciado, dizendo que só devolveria se recebesse o seu dinheiro (fl. 4).

Contudo, o denunciado passou a lutar com a vítima, que, então, amassou o instrumento ótico e o devolveu ao denunciado.

Irresignado ante o comportamento da vítima, com evidente "animus necandi", o denunciado muniu-se de um canivete (fl. 9) e partiu ao en- contro de Marcelo, que se pôs a correr e caiu ao solo, quando foi mortalmente golpeado no peito e no braço direito (Auto de Exame Cadavérico de fl. 32).

\section{IV.}

Assim, em se tratando das travestis, no nosso ponto de vista, das duas uma: ou a humanidade é um direito garantido a todos/as ou ao contrário apenas uma benesse concedida a alguns jurídica e socialmente assim reconhecidos/as. Portanto, no caso da morte social, que quase sempre coincide com a literal, parece que outra opção não há para as travestis. Em outras palavras: ou elas são mortas literalmente em situações de execução sumária com ou sem vínculo necessário com a prostituição, ou são mortas social e juridicamente já que a elas é previamente negado o direito de ser o que são, como são, como se percebem. Ora, não seria essa negação de humanidade tão ou mais violenta do que a morte cotidiana à que estão submetidas? Não estaria o regime jurídico que busca possibilitar a garantia de direitos fundamentais da pessoa humana, agindo ao seu revés? Como não pensar a invisibilidade ou mesmo a ausência das travestis nos espaços socialmente "democráticos", como escolas e universidades? Na verdade trata-se de uma ausência ou de uma interdição socialmente dada e consensualmente estabelecida e reiterada. Em cena a seguinte constatação: a inexistência de reconhecimento social que é produzida pelos discursos de competência e reiterada pelos imaginários sociais do "senso comum" torna os processos de exclusão, de silenciamento e de invisibilidade das travestis, concretos e visíveis. Afinal, inumanos não são humanos, portanto, não gozam do estatuto de cidadania. E se participam em alguma medida da condição de humanidade/cidadania, o que de modo geral não acontece, é apenas nos termos de uma lógica de controle, classificação e "cuidado" onde não há espaço para a indefinição e para a polissemia. Em dada medida ambas rimam com desordem e sujeira.

Finalizando, retomamos a remissão à decisão de Roger Raupp Rios, no julgamento em que ele estendeu às transexuais o direito de reconstruir através de cirurgia 
paga pelo SUS, seus sexos. Rios nos alerta quanto às armadilhas do conceito de gênero quando nos deparamos com as travestis.

Para os direitos das travestis, o reforço do binarismo de gênero é ainda mais violento. As travestis, encarnando quiçá a experiência mais radical da autonomia individual diante das convenções sociais sobre o que é padronizado como "natural" quanto ao sexo e sobre o que é tolerável pelos padrões tradicionais e dominantes de convívio entre homens e mulheres, ousam inventar um novo modo de ser em termos de gênero, transitando verdadeiramente nas "fronteiras do gênero" (para usar a expressão de Maria Luiza Heilborn, 'Gênero e Sexo dos Travestis', Sexualidade, Gênero e Sociedade, Rio de Janeiro: IMS-UERJ, no 7-8). Trata-se de uma construção de si peculiar e original, onde, do ponto de vista do gênero, os indivíduos travestis se constroem pelo feminino. Nas palavras de Marcos Benedetti, "o feminino travesti", onde, "ao mesmo tempo em que produzem meticulosamente traços e formas femininas no corpo, estão construindo e recriando seus valores de gênero, tanto no que concerne ao feminino como ao masculino. A ingestão de hormônios, as aplicações de silicone, as roupas e os acessórios, o acuendar a neca, as depilações são momentos de um processo que é maior e que tem por resultado a própria travesti e o universo que ela cria e habita." (Toda Feita - o corpo e o gênero das travestis, Rio de Janeiro: Garamond, 2005, p. 131). Como alertei logo acima, o reforço do binarismo de gênero em face das travestis incentiva todo o tipo de violência contra estes indivíduos: desde a desqualificação moral mais intensa até o freqüente assassinato, as travestis são vítimas número um da violência discriminatória. (RIOS, 2008, s/p).

Portanto, resta-nos dizer que a tarefa que nos cabe em termos de aplicação da categoria analítica do gênero e sua intersecção com outros vetores, tais como: raça, etnia, classe e geração, ainda é árdua, pois se enquanto mulheres, negras, idosas, heterossexuais, transexuais, quiçá homossexuais, avanços podem ser sentidos com a própria Lei Maria da Penha, é esta mesma lei e sua aplicação que pode reproduzir preconceitos que atingem "sujeitos inumanos" (por mais paradoxal que esta expressão possa ser), como as travestis, que ousam demandar ou adentrar em espaços onde elas são mortas socialmente e civilmente. ${ }^{15}$ Assim, em meio aos "Ts" da sigla LGBT, lembremos que no caso das "trans", a intervenção cirúrgica e a mudança do registro de nascimento podem significar sua inserção dentro do universo da lógica de cidadania heteronormativa. No caso das travestis, infelizmente essa cidadania e humanidade são-lhes negada, face às suas resistências a adequarem-se à lógica da definição existencial, com sua vivência de um estilo de vida geralmente compreendido como "desviante". Nesse sentido, cabe perguntarmos em que medida os dispositivos legais, ao pressuporem critérios a serem seguidos por quem almeja uma "cidadania" igualitária, portanto, uma humanidade, não acabam por criar justamente o contrário: a naturalização da desigualdade e a justificação das violências que busca enfrentar e sanar. Resposta já compartilhada ao longo de nossos escritos.

Diante de tantos impasses, poderíamos indagar o porquê da necessidade do reconhecimento de uma humanidade a grupos considerados socialmente como inumanos já que a política oficial desses dispositivos jurídico-normativos continua presa a noções essencializadoras e substancializadoras, tais como "sexo verdadeiro", o "gênero verdadeiro", "identidade verdadeira". Contudo, toda essa biopolítica, nos termos de Foucault, não está plenamente definida. Pelo contrário, aponta para as fissuras, as contradições, as ambiguidades, as entrelinhas, os entrelugares, e talvez seja justamente nessas margens que a mudança do próprio aparato normativo pode se constituir. Se de um lado, somos levados a pensar que a política do gênero como uma tentativa de determinação de um padrão de comportamento em que está em jogo uma identidade previamente definida leva à naturalização e à essencialização dos "papéis" de homens e mulheres, de outro lado, temos de levar em conta que as categorias são produtos sociais e enquanto tais passíveis de novos entendimentos e ressignificações. Se, conforme acreditamos, "rotular alguém, homem ou mulher, é uma decisão social" (FAUSTO-STERLING, 2001, p. 15), trata-se de pensar e repensar em que medida o aparato jurídico, enquanto produto de uma ideologia heteronormativa, teria condições de dar conta das experiências de vida que permanecem à margem das classificações. Portanto, não haveria espaço para outros modelos de humanida- 
de, baseado em sentidos outros? Judith Butler (2003), ao refletir sobre a reivindicação do movimento homossexual em torno do reconhecimento de suas uniões estáveis, problematiza(va) em que medida o movimento homossexual não estaria submetendo-se aos mesmos modelos aos quais historicamente tem buscado enfrentar e a se contrapor. Para a autora, não podemos ignorar a existência de "relações de parentesco que não se enquadram no modelo de família nuclear e que se baseiam em relações biológicas e não biológicas, ultrapassando o alcance das concepções jurídicas" (BUTLER, 2003, p. 221). Talvez aqui esteja a saída para o impasse - embora não sem impasses.

Portanto, qual é a importância do conceito de gênero frente a estes discursos de competência, como, o médico e o jurídico-legal? Pensamos que ele contribui para que percebamos que há existências não reconhecidas que não estão pautadas no binômio Homem ou Mulher, Heterossexual ou Homossexual, enfim, nas dicotomias excludentes. Neste sentido, a imensa tarefa que compete a este discurso também competente que é o acadêmico nos parece que reside no compromisso de fomentarmos não apenas o rompimento da subordinação das mulheres nascidas com vagina frente às relações cotidianas de desigualdades vividas com os homens nascidos com pênis. À luz deste raciocínio, ao nos reportarmos à lei Maria da Penha, pensamos que o movimento de reflexão se faz imprescindível para que o gênero lá constante estenda-se também às transexuais não cirurgiadas e às travestis. Caso contrário, incorremos no grande equívoco de carimbarmos com o estigma de inumanidade esses sujeitos, que enquanto inumanos não apresentam quaisquer direitos conhecidos como HUMANOS, pois para termos direitos humanos a serem exigidos do ESTADO devemos ser HUMANOS. Talvez este movimento reflita bem o desafio de pensarmos com os nossos instrumentos acadêmicos e "educacionais" ações afirmativas voltadas ao reconhecimento e ao respeito da diversidade.

\section{Notas}

1 Sob a coordenação de uma das autoras, os referidos projetos de extensão contaram com fomento da Pro - Reitoria de Extensão (PROEX) da UFGD.
20 referido projeto foi fundamental para a elaboração do atual que recebe auxílio via bolsa de produtividade do CNPq.

3 Ao nos referirmos que a banalização das violências praticadas contra as mulheres deixa em tese de existir, não desconsideramos que a simples retirada destes crimes dos Juizados Especiais Criminais apresenta o condão de modificar a visão de muitos dos operadores do direito que tratavam tais práticas como "crime de menor potencial ofensivo". Em 2015 foi aprovada a inserção da qualificadora no crime de homicídio no Código Penal Brasileiro, também conhecida como Lei do Feminicídio. Sua aprovação ainda sem maiores balanços, a priori, traz o retrocesso de não fazer uso em seu conteúdo do termo "gênero", se comparada à Lei Maria da Penha. Porém, com o advento da Lei Maria da Penha e seus dez anos de aplicação, o feminicídio que é todo e qualquer homicídio que ocorrer em virtude "da condição do sexo feminino" deve ser tão desconstruído quanto a própria categoria gênero se tomada de maneira binária. Algo explorado ao longo desse artigo, sem que venhamos a imergir na alteração do Código Penal quanto ao feminicídio por toma-lo como não dissociável de nossas análises.

4 A referida menção à Joan Scott diz respeito ao seu artigo "gênero uma categoria útil de análise histórica", publicado em português no início da década de 90 do século passado.

5 Destacamos que as pesquisadoras que se debruçam sobre temáticas como as trabalhadoras rurais em acampamentos ou assentamentos, tecem críticas importantes em relação à categoria gênero, pois neste espaço muitas das lutas das mulheres são obscurecidas frente ao uso do termo gênero que se subsume às reivindicações pautadas na "classe social" encampadas pelos assentamentos vinculados ao MST e à CUT. Por conseguinte, reiteramos os dizeres de Maria Ignez Paulilo:

Os primeiros estudos feministas nas Ciências Sociais receberam o nome de Sociologia e/ou antropologia "da mulher". Porém, o texto bastante conhecido da historiadora Joan Scott no qual ela faz considerações sobre a importância da categoria "gênero" como instrumento de análise tornou rapidamente obsoleto o uso da primeira denominação. Nas palavras da autora, "o gênero é um elemento constitutivo de relações sociais fundadas sobre as diferenças percebidas entre os sexos, e o gênero é um primeiro modo de dar significado às relações de poder".

Apesar da quase unanimidade sobre a importância de se usar a categoria gênero em vez de "mulher", concordamos com Cláudia de Lima Costa, quando ela diz que a adoção do conceito de gênero por parte dos Estados e das agências intergovernamentais nas Américas fez com que a crítica feminista à opressão e à subordinação da mulher tenha se diluído e sido neutralizada nos discursos e nas práticas dessas instituições. Daí a autora conclui que "o gênero enquanto categoria permitiu uma certa despolitização dos estudos feministas na academia latino-americana. (PAULILO, 2004, p.237). 
$6 \mathrm{O}$ artigo de Joan Scott denominado de "Gênero uma categoria útil para a análise histórica", como antes mencionamos, foi originariamente publicado na língua portuguesa no início da década de noventa do século passado, pela revista Educação e Realidade. Entretanto, fazemos menção à sua versão disponível na internet, frente ao fato de seu acesso se tornar mais facilitado por parte do público em geral.

7 Para ilustrar de maneira sintética o que se conhece por fenótipos na linguagem médica.

8 Conforme John Austin (1990), "dizer é fazer". Portanto, a nomeação, como elemento classificatório é responsável por uma inteligibilidade que além de dar sentido às coisas, cria a própria realidade existente. Nesse sentido, ser nomeado de homem ou de mulher, torna-se "imprescindível", para localizar socialmente o lugar de cada um na esfera do social. Eis uma das bases teóricas bebidas por Judith Butler ao expor que o gênero é performativo (BUTLER, 2003).

9 Frente à crítica elaborada por teóricas como Cláudia de Lima Marques antes exposta pela socióloga Maria Ignez Paulilo, tendemos a pensar que para minimizar as desigualdades vividas por trabalhadoras rurais de assentamentos, vinculados ao MST e à CUT, bem como, a determinadas vivências de mulheres quilombolas e indígenas, não necessariamente faz parte desta compreensão mais elástica ou ampla do conceito de gênero. Exceto, se a estas discussões viermos a agregar àquelas desenvolvidas no âmbito jurídico que propõe a desconstrução dos padrões hegemônicos como a heterossexualidade, o ser homem, caucasiano e rico, dentre outros vetores. Tais discussões serão abordadas mais adiante.

10 Os termos humanos e inumanos são tomados com base em Judith Butler (2005), que os utiliza tendo como objeto analítico as normas, e, então, (im)plicitamente o universo jurídico e legal. Além disto, Butler toma a inumanidade (2003) como aqueles corpos abjetos, cujas vidas são mais precárias que outras para o crivo do Estado. Em síntese, o crivo baliza-se pela razão seguinte: quanto mais incoerente é o sujeito em termos de sexo, gênero e desejo, considerando vetores de raça, etnia e classe social, mais inumano o é.

11 Indicamos para consulta e leitura a produção da antropóloga Paula Sandrine Machado (2005).

12 Por mais que em seu instigante artigo o antropólogo Mott congregue as discriminações sofridas por transexuais e travestis sob a insígnia da homossexualidade, como estamos fazendo a distinção entre sexualidade e gênero, tal distinção aqui remarcada em comparação àquela do referido pesquisador se faz necessária. Motivo pelo qual, não estamos a questionar os argumentos construídos pelo mesmo ao afirmar que os homossexuais em nossa sociedade são os mais odiados.
13 Nesse Estado consultar o trabalho de Simone Becker (2008).

14 Para maiores esclarecimentos sobre o TJMS e as travestis consultar artigo de Simone Becker e Hisadora B G Lemes (2014).

15 Como a aprovação da complementação da lei do homicídio também conhecida como Lei do Feminicídio.

\section{Referências Bibliográficas}

BLAY, Eva Alterman. Assassinato de mulheres e direitos humanos. São Paulo, Editora 34, 2008.

BECKER, Simone; LEMES, Hisadora B. G. "Vidas Vivas Inviáveis: Etnografia Sobre os Homicídios de Travestis no Tribunal de Justiça de Mato Grosso do Sul". Revista Ártemis, v.18, p.184 - 198, 2014.

BECKER, Simone. DORMIENTIBUS NON SOCURRIT JUS! (O DIREITO NÃO SOCORRE OS QUE DORMEM): um olhar antropológico sobre rituais processuais judiciais (envolvendo o pátrio poder/poder familiar) e a produção de suas verdades, 2008. Tese (Doutorado em Antropologia Social) - Programa de Pós Graduação em Antropologia Social, Centro de Filosofia e Ciências Humanas da UFSC, Santa Catarina.

BECKER, Howard. Outsiders: estudos de sociologia do desvio. Rio de Janeiro: Jorge Zahar Editor, 2008.

BENEDETTI, Marcos. Toda feita: O corpo e o gênero das travestis. Rio de Janeiro: Garamond, 2005.

BOURDIEU, Pierre. A Economia das trocas lingüísticas. O que falar quer dizer. São Paulo: Edusp, 1998.

BOURDIEU, Pierre. A Dominação Masculina. Rio de Janeiro: Bertrand Brasil, 1999.

BUTLER, Judith. Problemas de gênero. Feminismos e subversão da identidade. Rio de Janeiro: Civilização Brasileira, 2003.

BUTLER, Judith. O parentesco é sempre tido como heterossexual? In: Cadernos Pagu (21), Campinas, NEG/UNICAMP, 2003: pp.219-260.

. Humain, Inhumain. Le travail critique des normes. Entretiens. Paris: Éditions Amsterdam, 2005.

CHAUI, Marilena. Cultura e democracia: o discurso competente e outras falas. $3^{a}$ edição. São Paulo: Editora Moderna, 1982.

CRUZ, Rubia Abs da, et al. Nominando o inominável: violência contra a mulher e o poder judiciário. Porto Alegre: THEMIS, 2008.

DA SILVA, Irineu João. Recurso Criminal dos autos do processo sob o n² 2008.015632-5. Disponível em: http://app.tjsc.jus. br/jurisprudencia/acnaintegra!html.action?qID=AAAG\%2B9A AKAAAokzAAB\&qTodas $=$ travestis $+\& q$ Frase $=\& q U m a=\& q C o r=$ FF0000. Acessado em: maio de 2009. 
DOUGLAS, Mary. Pureza e perigo. São Paulo: Perspectiva, 1976.

FAUSTO-STERLING, Anne. Dualismos em duelo. In: Cadernos PAGU, vol 17/18. Campinas, NEG/UNICAMP, 2001.

FOUCAULT, Michel. Herculine Barbin: o diário de um hermafrodita. Rio de Janeiro: Francisco Alvez, 1982.

FOUCAULT, Michel. Vigiar e Punir: História da violência nas prisões. 29 ed. Petrópolis: Vozes, 2004.

FOUCAULT, Michel. História da sexualidade: a vontade de saber. 18 ed. Rio de Janeiro: Graal, 2007.

FOUCAULT, Michel. O nascimento da clínica. 6 ed. Rio de Janeiro: Forense Universitária, 2008.

FOUCAULT, Michel. Em defesa da sociedade. São Paulo: Martins Fontes, 2010.

MACHADO, Paula Sandrine. O sexo dos anjos: um olhar sobre a anatomia e a produção do sexo (como se fosse) natural. In: CADERNOS PAGU, (24), janeiro-junho 2005, pp. 249-281.

MOTT, Luiz. "Por que os homossexuais são os mais odiados dentre todas as minorias?". In:Corrêa, Mariza (Org). Gênero e Cidadania. Coleções Encontros. PAGU/Núcleo de Estudos de Gênero: UNICAMP, 2003, pp. 143-156.

OLIVEIRA, Esmael Alves de. Homofobia na escola: Algumas reflexões. In: BEZERRA, Giovani Ferreira (Org.). Pesquisa(s) em educação: múltiplos olhares. Curitiba: CRV, 2014.

PAULILO, Maria Ignez. Trabalho familiar: uma categoria esquecida de análise. In: REVISTA DE ESTUDOS FEMINISTAS. Volume 12, n.1. janeiro-abril. FLORIANÓPOLIS: UFSC, 2004, pp. 229-252.

REIS, Regina Helena Ramos. Parecer concedido na apelação cível dos autos do processo sob o $\mathrm{n}^{\circ}$ 31844-5/2006. Disponível em: http://www.mp.ba.gov.br/atuacao/caocif/registro/pareceres/ mudanca_sexo_prenome.pdf. Acessado em: setembro de 2008.

RIOS, Roger Raupp. Recurso de Apelação Cível dos autos do processo sob o no 2001.71.00.026279-9/RS. Disponível em: www.prr4.mpf.gov.br/pesquisaPauloLeivas/arquivos/acordao_ transexuais.pdf -. Acessado em: setembro de 2008.

RIOS, Roger Raupp \& PIOVESAN, Flávia. A discriminação por gênero e por orientação sexual. In: Série Cadernos do CEJ, volume 24, 2003, pp.255-275.

SCOTT, Joan. "Gênero uma categoria útil para a análise histórica". Disponível em: www.dhnet.org.br/direitos/textos/generodh/gen_categoria.html. Acessado em: janeiro de 2009.

SCOTT, John. 50 grandes sociólogos contemporâneos. São Paulo: Contexto, 2009.

SOUZA, Luiz Antônio de \& KÜMPEL, Vítor Frederico. Violência doméstica e familiar contra a mulher: Lei 11.340/2006. 2a edição. São Paulo: Editora Método, 2008.
TONELI, Maria Juracy Filgueiras. Diversidade sexual humana: notas para a discussão no âmbito da psicologia e dos direitos humanos. In: PSICOLOGIA CLÍNICA. Volume 20, n.2. Rio de Janeiro: PUC/RJ, pp.61-74.

Recebido em 10 de junho de 2016.

Aceito em 12 de julho de 2016. 
